\title{
ICMI Awards Report
}

\author{
Carolyn Kieran
}

A wonderful part of the opening session of the ICME congresses is the ICMI Awards ceremony. The 2012 ceremony, which was presided over by Prof. Carolyn Kieran, the chair of the ICMI Awards Committee, was no exception. Congress participants shared in congratulating the recipients of the 2009 and 2011 competitions for the Klein and Freudenthal awards. The Korean Minister of Education, Science, and Technology, the Honorable Mr. Ju-Ho Lee, did us the honor of presenting each award.

In 2000, the International Commission on Mathematical Instruction decided to create two prizes given in recognition of outstanding achievement in mathematics education research:

- the Felix Klein Award, which honours lifetime achievement in our field, and

- the Hans Freudenthal Award, which honours a major cumulative programme of research.

Each award consists of a medal and a certificate, accompanied by a citation. The two awards are given in odd-numbered years. A six-person Awards Committee is responsible for selecting the awardees and for producing the citations explaining the merits of the awardees. The members, of whom only the Chair is known, are appointed by the President of ICMI and serve on the Committee for 8 years.

Scientific and scholarly quality is of course the fundamental characteristic involved in reviewing the candidates' work and merits. The first Committee, which was appointed in 2002, agreed on four aspects of quality, four criteria of evaluation: impact, sustainability, depth, and novelty. These criteria have been maintained throughout the Committee's work. Nevertheless, the field is influenced by social and cultural conditions, traditions, values, norms, and priorities. So, there are, inevitably, delicate balances to be struck between different dimensions, different traditions, different cultural and ethnic regions, and-indeed-different schools of

C. Kieran (ه)

Université du Québec à Montréal, Montréal, QC, Canada

(C) The Author(s) 2015

S.J. Cho (ed.), The Proceedings of the 12th International Congress

on Mathematical Education, DOI 10.1007/978-3-319-12688-3_5 
thought. Past Klein awardees have been Guy Brousseau (2003), Ubiritan D'Ambrosio (2005), and Jeremy Kilpatrick (2007). Past Freudenthal awardees have been Celia Hoyles (2003), Paul Cobb (2005), and Anna Sfard (2007).

At the 2012 ICMI Awards ceremony, the following four individuals were honored for their contributions to the field.

- The Felix Klein Medal for 2009: awarded to IAS Distinguished Professor and Professor Emerita Gilah C. Leder, La Trobe University, Bundoora, Victoria, Australia.

- The Hans Freudenthal Medal for 2009: awarded to Professor Yves Chevallard, IUFM d'Aix-Marseille, France.

- The Felix Klein Medal for 2011: awarded to the Elizabeth and Edward Connor Professor of Education and Affiliated Professor of Mathematics, Alan H. Schoenfeld, University of California at Berkeley, USA.

- The Hans Freudenthal Medal for 2011: awarded to Professor Luis Radford, Université Laurentienne, Sudbury, Canada.

Gilah Leder's citation, which was read by ICMI President Bill Barton, acknowledged her more than thirty years of sustained, consistent, and outstanding lifetime achievement in mathematics education research and development. Her particular emphasis on gender success and equity in mathematics education, but also more broadly her work on assessment, student affect, attitudes, beliefs, and self-concepts in relation to mathematics education from school to university, as well as her research methodology, and teacher education, have contributed to shaping these areas and have made a seminal impact on all subsequent research.

Yves Chevallard's citation, which was read by ICMI Vice-President Mina Teicher, recognized his foundational development of an original, fruitful, and influential research programme in mathematics education. The early years of the programme focused on the notion of didactical transposition of mathematical knowledge from outside school to inside the mathematics classroom, a transposition that also transforms the very nature of mathematical knowledge. The theoretical frame was further developed and gave rise to the anthropological theory of didactics (ATD), which offers a tool for modelling and analysing a diversity of human activities in relation to mathematics.

Alan Schoenfeld's citation, which was read by ICMI Past-President Michèle Artigue, recognized his more than thirty years of scholarly work that has shaped research and theory development in mathematical learning and teaching. His fundamental theoretical and applied work that connects research and practice in assessment, mathematical curriculum, diversity in mathematics education, research methodology, and teacher education has made a seminal impact on subsequent research. Another significant component of his achievements has been the mentoring he has provided to graduate students and scholars, nurturing a generation of new scholars.

Luis Radford's citation, which was read by ICMI Vice-President Angel Ruiz, acknowledged the outstanding contribution of the theoretically well-conceived and highly coherent research programme that he initiated and brought to fruition over 
the past two decades. His development of a semiotic-cultural theory of learning, rooted in his interest in the history of mathematics, has drawn on epistemology, semiotics, anthropology, psychology, and philosophy, and has been anchored in detailed observations of students' algebraic activity in class. His research, which has been documented in a vast number of scientific articles and in invited keynote presentations, has had a significant impact on the community.

The image of the four awardees standing on the stage together, receiving their medals and accompanying certificates from the Minister of Education-as well as the beautiful bouquets of flowers presented by young Koreans in traditional dressis one that will stay with us for quite some time.

Open Access This chapter is distributed under the terms of the Creative Commons Attribution Noncommercial License, which permits any noncommercial use, distribution, and reproduction in any medium, provided the original author(s) and source are credited. 